\title{
Allocation of Scarce Resources After a Nuclear Detonation: Setting the Context
}

Ann R. Knebel, DNSc, RADM-USPHS; C. Norman Coleman, MD; Kenneth D. Cliffer, PhD; Paula Murrain-Hill, MPH; Richard McNally, MS; Victor Oancea, PhD; Jimmie Jacobs, PhD; Brooke Buddemeier, CHP; John L. Hick, MD; David M. Weinstock, MD; Chad M. Hrdina, MS; Tammy Taylor, PhD; Marianne Matzo, PhD; Judith L. Bader, MD, CAPT-USPHS; Alicia A. Livinski, MPH; Gerald Parker, DVM; Kevin Yeskey, MD

\section{ABSTRACT}

The purpose of this article is to set the context for this special issue of Disaster Medicine and Public Health Preparedness on the allocation of scarce resources in an improvised nuclear device incident. A nuclear detonation occurs when a sufficient amount of fissile material is brought suddenly together to reach critical mass and cause an explosion. Although the chance of a nuclear detonation is thought to be small, the consequences are potentially catastrophic, so planning for an effective medical response is necessary, albeit complex. A substantial nuclear detonation will result in physical effects and a great number of casualties that will require an organized medical response to save lives. With this type of incident, the demand for resources to treat casualties will far exceed what is available. To meet the goal of providing medical care (including symptomatic/palliative care) with fairness as the underlying ethical principle, planning for allocation of scarce resources among all involved sectors needs to be integrated and practiced. With thoughtful and realistic planning, the medical response in the chaotic environment may be made more effective and efficient for both victims and medical responders.

(Disaster Med Public Health Preparedness. 2011;5:S20-S31)

Key Words: nuclear detonation, triage, scarce resources

E ffective preparation for a nuclear detonation requires an understanding of the physical damage and spectrum of victims associated with the incident and the concept of how to effectively allocate scarce resources to save lives. Immediately after the detonation and for days thereafter, major interruptions and shortages of medical resources for the casualties closest to the detonation site will occur. These casualties will surge into hospitals already treating patients. This will inevitably necessitate implementation of crisis standards of care. ${ }^{1}$ Although the immediate vicinity of the detonation will sustain extensive damage, the surrounding areas will be physically intact, so regional resources can be applied to the initial surge. Damage to transportation routes may make it difficult, however, to bring resources to bear in the initial hours and days after the detonation. Over time, additional resources will be provided and the standards of care will return to usual.

The information in this article is obtained from key resources ${ }^{2-13}$ that set the context for understanding the issues surrounding allocation of scarce resources in this type of incident. The casualty estimates indicate that many tens of thousands of people would need medical care and many hundreds of thousands would be concerned that they do. Determining how to triage patients and maximize available resources to deliver medical care to these casualties using the ethical principle of fairness is the focus of this special issue of Disaster Medicine and Public Health Preparedness. ${ }^{14}$

\section{PHYSICAL EFFECTS OF THE DETONATION}

Effects of a Nuclear Detonation: 10-kiloton Surface Burst ${ }^{2}$ Nuclear detonations are characterized based on their yield, which is specified as the equivalent amount of trinitrotoluene that would result in a blast of similar force. A $10-\mathrm{kT}$ size is chosen for illustration purposes for this article because it is within the range of possibilities and has been used in the National Planning Scenarios. ${ }^{6}$

A nuclear detonation produces various effects including thermal energy, blast effects, and ionizing radiation, with radiation being both prompt from the detonation and prolonged from fallout/groundshine. The relative contribution of each effect on human casualties is markedly affected by yield, whether the burst occurs at ground level or in the air (elevation), population density, weather conditions, and the physical environment (eg, dense urban buildings with intervening "canyons," vs more open spaces). ${ }^{15}$

A ground burst produces radioactive fallout by sucking ground materials up into the fireball and distributing them over time, particularly via high-altitude prevailing winds. An air burst produces less fallout, but it results in exposure of more people to direct thermal and radiation effects. The partitioning of the energy of a $10-\mathrm{kT}$ nuclear detonation is described in the following pages. 


\section{Blast}

The primary effect of a nuclear detonation is the blast originating from the rapidly expanding fireball, which generates a pressure wavefront moving rapidly away from the point of detonation. Blasts are measured by overpressure (air pressure in excess of normal ambient air pressure) and dynamic pressure (wind generated by the passing pressure wave). Initially, near the point of detonation for a surface nuclear burst (ground zero), the overpressure is extremely high, thousands of pounds per square inch, expanding in all directions from the detonation at hundreds of miles per hour. With increasing distance from ground zero, the overpressure and speed of the blast wave dissipate, until they cease to be destructive.

Accompanying the overpressure wave is dynamic pressure, a wind of extremely high velocity associated even with relatively low overpressure. ${ }^{2}$ The combination of overpressure and wind is extremely destructive to structures. ${ }^{2}$ For example, at 5 psi, the wind velocity may reach more than $160 \mathrm{mph}$, which would be about $0.6 \mathrm{mi}$ from ground zero. Previous nuclear tests and computer models aid in impact estimation, but contemporary buildings may react differently than buildings observed in older tests.

\section{Thermal Energy}

The initial intense thermal pulse of energy in air (from the nuclear flash at ground zero) is able to instantaneously incinerate infrastructure and cause flash burns in people. Flash burns may result from direct blast-associated thermal injury to the skin or from heating or ignition of clothing. The potential for fire ignition in modern cities from thermal effects is poorly understood. Nonetheless, secondary fires may be started by the thermal pulse or as a result of the blast. These would result in "flame burns."

\section{Light Energy}

The 10-kT nuclear detonation produces a fireball of incandescent gas and vapor. Initially, the fireball is many times more brilliant than the sun at noon, but quickly decreases in brightness as it continues to expand over time. Exposed eyes are at risk of permanent retinal burns and flash blindness out to relatively great distances (especially at night, when the pupil is dilated). Flash blindness, usually temporary, results from viewing intense light that was scattered before it reached the eye. Under conditions of good visibility ( $80 \mathrm{~km}$, or $50 \mathrm{mi}$ ), the $10-\mathrm{kT}$ explosion could produce flash blindness out to a distance of 12 $\mathrm{km}(7 \mathrm{mi})$ during the day and $24 \mathrm{~km}(15 \mathrm{mi})$ at night. Individuals who directly view the initial fireball could experience retinal burns out to a distance of $110 \mathrm{~km}(68 \mathrm{mi})$.

\section{Ionizing Radiation}

A 10-kT blast results in 2 sources of radiation exposure: prompt and fallout/groundshine. Prompt radiation is released within fractions of a second from the blast itself. The detonation also creates fission products that attach to debris from the ground that rises into the air and is carried by upper atmospheric winds. As this radioactive material settles, it is called radioactive fallout. In addition, neutrons from the detonation can make the ground radioactive. Fallout plus neutron-activated material constitute what is called groundshine. Fallout is the main source of radioactive contamination of people and the environment after a nuclear detonation.

Fission products have a wide range of radioactive half-lives, from fractions of a second to years. Radiation injury is caused primarily by gamma and beta emissions, with neutrons being a minor component. Both prompt and fallout radiation can deliver acutely lethal radiation doses. Fallout will be the prime source for individuals sustaining radiation-only injury without trauma. Prompt radiation is likely to be accompanied by burns and trauma, because of the proximity of its victims to the detonation. Radiation injury plus burns and/or trauma is called combined injury, ${ }^{16}$ which has a higher fatality rate than either type of injury alone. The distribution and severity of human injuries depend on the physical factors and protection afforded by sheltering in place and shielding.

The radiation dose from fallout depends upon how much contamination an individual is exposed to over time spent in the contaminated area. The $\mathrm{LD}_{50}$ (lethal dose) is the radiation dose leading to fatality in half of the people exposed to it. For humans, the $\mathrm{LD}_{50}$ for instantaneous exposure without active rescue and medical care is thought to be about $350 \mathrm{cGy}$. The $\mathrm{LD}_{50}$ is higher and the radiation injury effects are less severe for a given dose for radiation delivered more slowly. Other factors that influence the value of the $\mathrm{LD}_{50}$ include shielding of part of the body from the full effects of radiation (resulting in inhomogeneous exposure), comorbid diseases, extremes of age, and individual biological variation. Nonetheless, for responseplanning purposes, an $\mathrm{LD}_{50}$ of about $350 \mathrm{cGy}$ is used, with the knowledge that $\mathrm{LD}_{50}$ is higher with vigorous supportive care, which may not be readily available in the period immediately after this type of incident.

\section{Electromagnetic Pulse}

People are not directly affected by the electromagnetic pulse (EMP); however, communications and other electronic equipment may be damaged. The EMP damage range for a $10-\mathrm{kT}$ detonation is approximately $4 \mathrm{~km}(3 \mathrm{mi})$. Not all equipment within the EMP-effects zone will fail. The likelihood of failure will increase the closer to ground zero the equipment is located, the larger the equipment's effective receptor antenna, and the greater the sensitivity of that equipment to EMP effects. In simulation studies, $65 \%$ of electronic medical equipment was damaged. ${ }^{15,17}$ This included direct damage to equipment and electric current surges. Cellular telephones and handheld radios have relatively small antennas and if they are not connected to electrical power supplies during the EMP pulse, they probably will not be affected by the EMP. Damage to medical equipment and reduced communications abilities will affect the ability to meet the demand for medical resources and 
result in the need to allocate the remaining resources according to a clearly identified scheme.

\section{Damage and Radiation Zones}

In the initial hours after a nuclear detonation, the response will be chaotic, and communications among responders may be unreliable. Dust and debris from the blast will make initial actions difficult and will add to the confusion. The results of a nuclear detonation at least initially will exceed the capabilities of local and regional resources, and federal assistance will be needed immediately to support states and localities in managing the great number of casualties. Even with federal assistance, the demand for resources clearly will exceed the capability to provide them, so planning for allocation of scarce resources will be necessary. Complicating the provision of resources will be the need to protect responders from the effects of radiation. Identification of the radiation levels will be done initially by first responders, firefighters, police, and other groups in the local/regional response, who have experts able to provide environmental radiation detection services and to identify perimeters. The federal response will be guided by the Nuclear/Radiological Incident Annex of the National Response Framework.?

Information on wind and fallout direction will be available from Department of Homeland Security-led Interagency Modeling and Atmospheric Assessment Center (IMAAC) ${ }^{18}$ soon after the detonation. The Department of Energy National Atmospheric Release Advisory Center serves as the operations hub for the IMAAC and will provide plume data to the local incident management team and the Department of Health and Human Services Secretary's Operations Center. The center will assess the data for potential effects on the public health and medical infrastructure. The dangerous fallout zone (see below), where people are at risk of acute radiation syndrome, should reach its maximal size after the first 1 to 2 hours. As a result of radioactive decay, the dose rate associated with a given amount of fallout will decline rapidly, falling $90 \%$ between 1 and 7 hours after the detonation. Due to windborne dispersal of radioactive material, the larger radiation caution zone within the $10 \mathrm{mR} / \mathrm{h}$-perimeter (see below) will increase in size, perhaps for a few days, and then later shrink due to ongoing radioactive decay. ${ }^{15,19}$

The Planning Guidance for Response to a Nuclear Detonation ${ }^{2}$ incorporates a zoned response concept (Figure 1) into which the medical response is embedded. Although Figure 1 shows circular damage zones, the actual shape of these zones will vary with terrain and structures that affect the distribution of blast effects. Early models and initial observations and measurements will delineate the zones that can then be used to plan response activities. Over time, further measurements will help determine the areas in which responders can safely provide care and with what degree of caution with respect to radiation levels.

Without radiation detection equipment, the type of physical damage can help in estimating radiation dose, although actual measurement is necessary for confirmation, and the potential for substantial radiation with little or no physical damage must be recognized. Understanding which zone patients were in for what length of time can help in assessing their potential radiation doses and thus assist in identifying their triage categories and their priorities for allocating scarce resources.

\section{Severe Damage Zone}

- Few, if any, buildings are expected to be structurally sound or even standing in the severe damage zone (the severe damage zone was formerly referred to as the "no-go" zone in the first edition of the Planning Guidance for Response to a Nuclear Detonation), and few people would survive; however, some people protected within stable structures (eg, subterranean parking garages, subway tunnels) at the time of the detonation may survive the initial blast.

- Extremely high radiation levels and other hazards are expected in the severe damage zone, making this zone gravely dangerous to survivors and responders; therefore, the severe damage zone should be considered a no-go zone during the early days after the detonation.

- Rubble in the streets is estimated to be impassable in the severe damage zone, making timely response impracticable. Approaching ground zero, all of the buildings will be rubble and rubble may be $\geq 30 \mathrm{ft}$ deep.

\section{Moderate Damage Zone}

- Responders may consider that they are transitioning into the moderate damage zone when building damage becomes substantial. This damage may correspond to a distance of about $1 \mathrm{mi}(1.6 \mathrm{~km})$ from ground zero for a $10-\mathrm{kT}$ nuclear detonation.

- Observations in the moderate damage zone include significant structural damage, blown-out building interiors, blowndown utility poles, overturned automobiles, caved-in roofs, some collapsed buildings, and fires. In the moderate damage zone, sturdier buildings (eg, reinforced concrete) will remain standing, lighter commercial and multiunit residential buildings may be fallen or structurally unstable, and many wood-frame houses will be destroyed.

- Within the moderate damage zone, broken water and utility lines are expected and fires will be likely.

- Many casualties in the moderate damage zone will survive and these survivors, in comparison to survivors in other zones, will benefit most from urgent medical care.

\section{Light Damage Zone}

- Damage is caused by shocks, similar to a thunderclap, but with much more force. Some windows may be broken more than $10 \mathrm{mi}$ away.

\section{Dangerous Fallout Zone}

- The dangerous fallout zone is distinguished not by structural damage but by fallout radiation levels. A radiation exposure rate of $10 \mathrm{R} / \mathrm{h}$ is used to delimit this zone. The dangerous fallout zone will be identified through IMAAC modeling ${ }^{18}$ or knowledge of the detonation location and prevailing winds. The National Atmospheric Release Advisory Center serves as the operations hub for IMAAC and will provide the plume models to the local incident 
management and the cooperating agencies in the Nuclear/Radiological Incident Annex of the National Response Framework. ${ }^{7}$ This will be crucial for communicating radiation dose-protection strategies to responders and the area population.

- Measurement from local responders is needed to verify location of the fallout.

- This zone is a hazardous area and it is important that responders refrain from undertaking missions in areas where radioactivity may be present until radiation levels can be accurately determined and readily monitored. The boundary of this zone will change rapidly (Figure 1B).

\section{Radiation Caution Zone}

- A perimeter of $10 \mathrm{mR} / \mathrm{h}(0.01 \mathrm{R} / \mathrm{h})^{2}$ can reach a maximum range of several hundred miles within a few days of

\section{FIGURE 1}

\section{Damage and fallout zones modeled for ground bursts ${ }^{2}$}

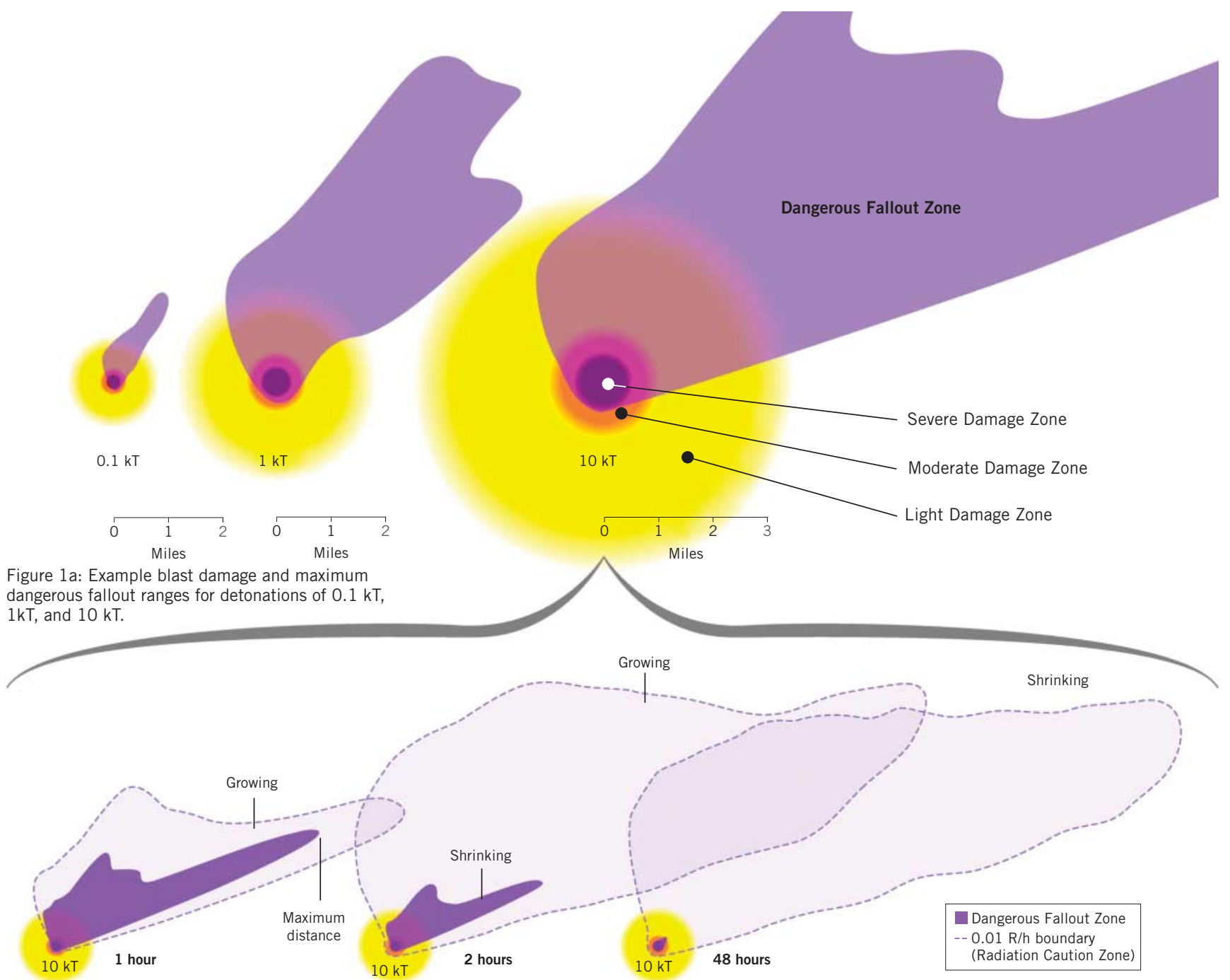

Figure 1a: Example blast damage and maximum dangerous fallout ranges for detonations of $0.1 \mathrm{kT}$, $1 \mathrm{kT}$, and $10 \mathrm{kT}$
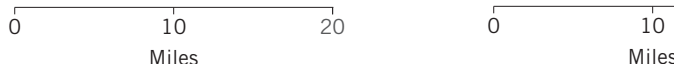

Approximate contamination levels. Actual levels would be dependent on yield and weather.

Figure 1b: Illustration of example projected fallout zone changes with time for a $10 \mathrm{kT}$ detonation.

A, Illustration for 3 different detonation yields $(0.1,1$, and $10 \mathrm{kT})$ of the projected extents of 3 major damage zones: severe, moderate, and light, and of the dangerous fallout zone. B, Example for a 10-kT detonation of how the dangerous fallout zone and the zone enclosed by the $0.01 \mathrm{R} / \mathrm{h}$ boundary (which may be considered a radiation caution zone) are projected to change over time. The dangerous fallout zone, where the high radiation level is most likely to cause acute radiation syndrome, begins to shrink soon after reaching its maximum size, about 1 hour postdetonation. The radiation caution zone enlarges as the fallout settles and then shrinks as the fallout dose rate decreases.

Figure Courtesy of Lawrence Livermore National Laboratory. 
the detonation. Although it has not been officially named in Planning Guidance for Response to a Nuclear Detonation, ${ }^{2}$ the zone within this perimeter and outside of the dangerous fallout zone may be considered a radiation caution zone. Emergency operations can be safely performed within this zone provided responders exercise appropriate caution and limit the time they spend in this zone, to avoid accumulating a dangerous dose through excessive exposure.

- Like the dangerous fallout zone, the radiation caution zone will begin to shrink after it reaches its maximum range (Figure $1 \mathrm{~B}$ ).

\section{Limiting Radiation Dose: Sheltering in Place}

Understanding the radiation risk and protective measures can reduce exposure and prevent unnecessary demand for resources. Prompt radiation is of short duration, lasting seconds after the detonation. Its intensity decreases with radial dis- tance away from ground zero and with radiation absorption, scattering, and capture by the atmosphere and buildings. The 3 factors that reduce radiation exposure are decreased time spent in contaminated areas, increased distance from areas where fallout accumulates, and increased shielding such as earth or thick walls between the fallout and the shelter location. Heavy buildings block significantly the direct path of prompt radiation and shield interior inhabitants from both prompt and delayed radiation. Figure 2 illustrates the dose-reduction factors for different locations within a heavily constructed building (right) and for various other types of structures.

Fallout dose rate declines rapidly over time. The dose rate falls by roughly $90 \%$ for every 7 -fold increase in time. ${ }^{2}$ This means that compared to what the dose rate was at 1 hour after the detonation, the dose rate from a given amount of fallout is $10 \%$ of that amount at 7 hours, $1 \%$ at 49 hours (roughly 2 days), and

FIGURE 2

\section{Dose-reduction factors}
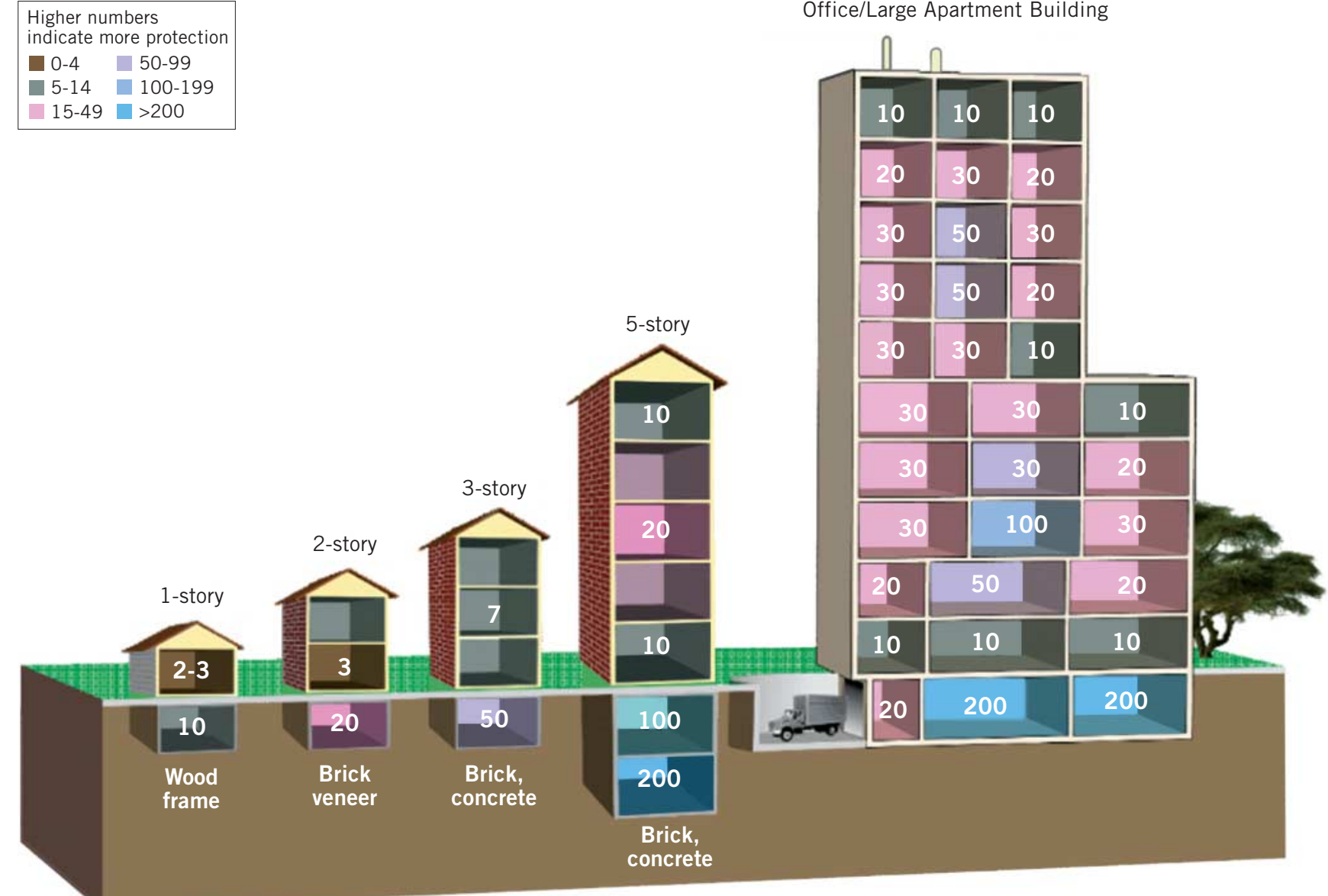

Building as shielding. Numbers represent dose reduction factors. A dose reduction factor of 10 indicates that a person in that area would receive 1/10th of the dose of a person in the open. 
$0.1 \%$ at 14 days. Thus, the greatest risk from fallout occurs in the first few hours.

The safest initial personal protective action is generally sheltering in a shielded location rather than evacuation, particularly in the period shortly after the detonation, when situational awareness is limited. The advice as to when to shelter in place and/or when to evacuate will depend on the person's location, type of shelter, distance from the shelter to a noradiation location, time after detonation, and other factors. Staying in a sheltered location in a heavily constructed building should be the initial default position. Additional information about public messaging for shelter in place can be found in Planning Guidance for Response to a Nuclear Detonation. ${ }^{2}$

\section{Assessing and Estimating Radiation Exposure}

Initial assessment of the dose of radiation exposure will depend on the person's physical location(s) during the incident. Where an individual was located in relation to ground zero and how long he or she was there will be considered, along with environmental radiation mapping information from various sources. The presence of trauma does not mean that the person has been exposed to radiation, just as the absence of trauma does not mean that the person has had no radiation exposure.

Laboratory support will be necessary to assist in the estimation of dose and optimal management of casualties. Given current capacity, laboratory analysis capabilities will be in short supply, so radiation doses will be estimated based on available information. A proposed radiation laboratory network would include hematology surge capacity for complete blood counts, cytogenetic biodosimetry, and newer high-throughput and pointof-care biodosimetry techniques under development. ${ }^{20,21}$ The assessment of radiation dose from internal contamination is not considered a major part of a nuclear detonation medical response, because significant internal contamination during the early response is expected to be rare..$^{22,23}$

\section{CASUALTY ESTIMATES}

\section{Estimates of Casualty Numbers}

Modeling efforts to scope the numbers and types of casualties resulting from urban nuclear detonations consider a wide range of casualty possibilities. Factors that can affect the casualty numbers include nuclear detonation yield, height of burst, population density, building types, and weather patterns. Because of the range of possibilities, casualty numbers for a given yield can vary by factors of 5 to $\geq 10$ among cities and among detonation locations within cities. The numbers and types of casualties presented in the present article are not tied to any specific location, but rather are presented as estimates to plan for the scarce resources environment associated with this type of incident.

The Table presents selected results from modeling of a range of 185 scenarios with various nuclear detonation yields (0.1-10 $\mathrm{kT}$ ), heights of burst (ground and air), and weather conditions, in several major US cities. The modeling was done by the modeling division of the Biomedical Advanced Research and Development Authority in association with the Public Health Emergency Medical Countermeasures Enterprise Blood and Tissue Requirements Working Group. The modeling is based partially on data and calculations shared in a coordinated way among government agencies (Departments of Defense, Homeland Security, and Health and Human Services). The results update estimates in the National Planning Scenario. ${ }^{6}$ The values in the Table represent a mid-range estimate (50th percentile), a moderately high-range estimate (85th percentile), and an estimate for a high-consequence scenario (95th percentile). Although these numbers are potentially sensitive to variations in the choice of scenarios that were modeled, a wide enough variety of potentially high-consequence scenarios was strategically chosen to provide a useful idea of what may be encountered in actual incidents. (Percentiles are for the wide variety of strategically selected scenarios that were modeled and not intended to indicate the likelihood of the event occurring.) An

\section{TABLE}

\section{Distribution of Casualties From Nuclear Detonation Modeling}

Injury Type
Trauma (ISS)
Burn (\% TBSA
partial- to
full-thickness)
Radiation dose
(cGy)

Combined injury (dose $>150$ cGy)

$\begin{array}{crrr} & & \text { Ground } \\ \text { Category } & \mathbf{5 0 \% \text { ile }} & \mathbf{8 5 \% \text { ile }} & \mathbf{9 5 \% \text { ile }} \\ \text { Mild (1-9) } & 18000 & 53000 & 79000 \\ \text { Moderate }(10-14) & 34000 & 119000 & 121000 \\ \text { Severe }(>15) & 14000 & 62000 & 143000 \\ \text { Mild (5-10) } & 0 & 0 & 0 \\ \text { Moderate }(10-30) & 0 & 0 & 60 \\ \text { Severe }(>30) & 0 & 0 & 0 \\ \text { Mild (75-150) } & 5000 & 32000 & 91000 \\ \text { Moderate }(150-530) & 7000 & 29000 & 51000 \\ \text { Severe, }(530-830) & 3000 & 9000 & 12000 \\ \text { Expectant (>830) } & 10000 & 28000 & 47000 \\ \text { Trauma and/ or burn (mild-severe) } & 3000 & 20000 & 44000\end{array}$

$50 \%$
28
36
18
2
1

Air
$85 \%$ ile
48000
80000
75000
0
1000
0
8000
12000
3000
5000
18000

$50 \%$ ile
20000
34000
14000
0
0
0
4000
6000
3000
5000
2000

Composite

$85 \%$ ile $\quad 95 \%$ ile

53000

$118000 \quad 121000$

$63000 \quad 143000$

132000

109000

3000

0

13000

20000

5000

10000

49000

$\begin{array}{rr}0 & 0 \\ 0 & 1000 \\ 0 & 0 \\ 23000 & 72000 \\ 25000 & 41000 \\ 6000 & 12000 \\ 16000 & 47000 \\ 20000 & 45000\end{array}$

ISS= Injury Severity Score; TBSA=Total Body Surface Area. 
important caveat is that incidents with consequences outside the range represented by the modeling results are possible.

After a nuclear detonation incident, many more people than those physically harmed will have urgent and reasonable concerns about their health. Among these will be people not directly affected by the incident but who have prior medical problems that have acutely worsened or who had treatment disrupted by the loss of medical infrastructure. In prioritizing scarce resources, these other patients as well as those directly injured in the incident need to be considered.

\section{Important Considerations}

- Categorizing injuries as mild, moderate, and severe requires setting somewhat arbitrary boundary criteria. The criteria used for the categorization for Table are noted within it. The casualty criteria for triage are described by Casagrande and colleagues. ${ }^{24}$
- The numbers of fatalities vary greatly in different modeled scenarios, mainly with the size and composition of the severe damage zone (including population density at the time of the detonation). However, the number and distribution of survivors and injuries, mostly from outside the severe damage zone, varies less.

- The number of burn victims to treat is limited by the presence of shielding due to buildings in an urban setting (the buildings also shield both prompt and fallout radiation exposure) and also because the overlap of serious radiation, trauma, and burn injuries within and near the severe damage zone produces immediate fatalities. In general, burns are much more common with an air blast, and radiation injury (resulting from fallout) is more common with a ground burst.

- Combined injury-radiation plus one or more other forms of trauma-has a worse prognosis than similar levels of any of the single types of injuries, although how much worse remains to be better determined.

\section{FIGURE 3}

\section{Overlay of the RTR system with the zoned approach}

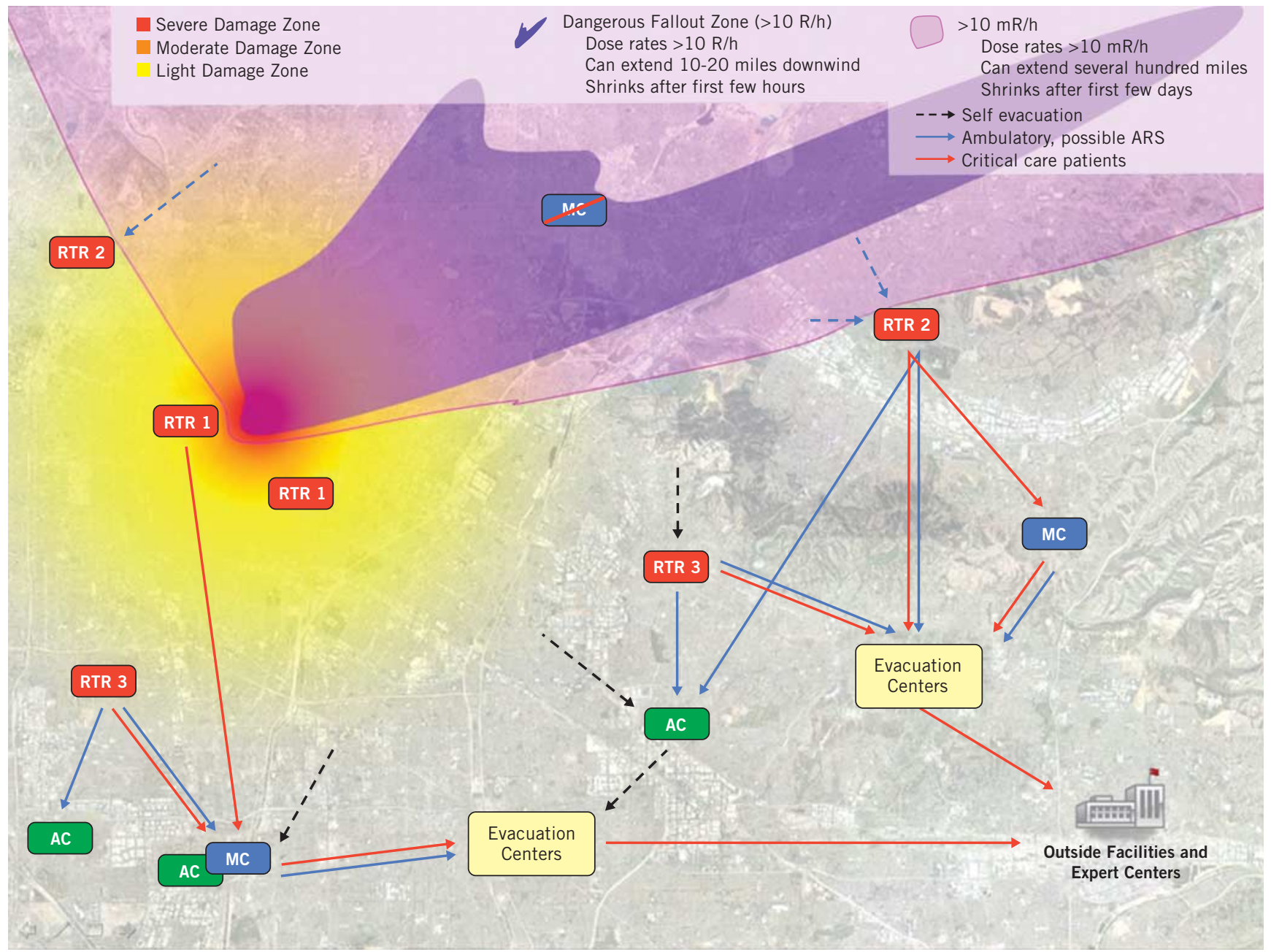


- After a detonation, "sizing" of the incident and determining the location of the various response zones and the fallout pattern will take time. The numbers in the Table should provide planners and responders some sense of the potential size of the medical response that could be needed.

\section{MEDICAL RESPONSE}

Medical management during the response will depend on the types of injuries sustained, on the number of each type of injury, and on the relative scarcity of resources, all of which will vary, at times substantially, with the distance from ground zero and with the time after the detonation.

The availability of medical resources to care for the casualties will depend on the organization of the surrounding area governments; modes and routes of transportation and access; and availability of medical facilities and emergency management assistance compacts for state-to-state mutual aid. ${ }^{25}$

For medical care and resources to be matched to the needs of the casualties a federal interagency medical response planning group developed a conceptual approach for responding to a nuclear detonation, ${ }^{26}$ the radiation treatment, triage, and transport (RTR) response system (see Figure 3). The purpose of the RTR system is to characterize, organize, and efficiently deploy appropriate materiel and personnel assets as close as possible to various categories of victims while preserving the safety of responders. RTR sites are formed spontaneously and determined in real-time by the incident commander and responders. Sites are designated based on their extent of physical destruction, the ongoing presence of radioactive groundshine and fallout, their accessibility to transportation, and the victim population types near these sites.

\section{RTR1}

RTR1 will be near the severe damage zone and within the moderate damage zone. RTR1 sites will have major structural damage, radiation, and a high number of fatalities, many with combined injury.

- At RTR1 sites, many or most affected people are nonambulatory, or soon will be; victims will have physical trauma, burns, acute radiation syndrome, and combined injuries.

- Based both on their proximity to the blast and time to onset of symptoms, many of the victims will clearly have lethal traumatic and/or radiation injuries and will require primarily comfort care, if available.

- Responders will not be able to enter RTR1 in the initial hours after the detonation, when resources are particularly limited.

\section{RTR2}

RTR2 sites will have limited or no physical damage, but may have radiation limiting the time for victims and responders to be present, with most victims being ambulatory. These may be just outside the moderate damage zone and also in and near the dangerous fallout zone. Patients at RTR2 sites will be treated for survivability, contingent on the availability of supplies and responders. These sites will have more supplies and responders than RTR1 sites.

- Most victims will be ambulatory, and many fewer victims will have combined injuries; many victims may have significant radiation exposure from fallout and will be at risk of developing acute radiation syndrome.

- The time constraints for responders must be carefully monitored due to ambient radiation, particularly if the site is within the dangerous fallout zone.

- Self-decontamination through removal of surface contamination will be possible once people are outside of the area.

- Transportation may be delayed.

- Available resources may be targeted within the sites to use the resources most effectively in the early hours after the detonation; triage protocols will allow for fairness in the allocation of limited resources.

\section{RTR3}

RTR3 sites may have some structural and broken glass damage; they may be where people spontaneously aggregate in the light damage zone or anywhere in the surrounding region, similar to collection points designated in some localities' existing mass casualty plans. Many people will have no need for medical care.

- Almost all of the victims will be ambulatory; many may have minor to no injuries and no significant radiation exposure, and some will be displaced people whose homes will be uninhabitable and/or unreachable for some period of time.

- The time constraints for responders' presence will reflect regular disaster shift schedules and will not be limited by ambient radiation; local physical dose monitors and radiation safety officers will alert the incident commander if the site becomes contaminated (contamination of the site may result in its movement to a clean location or in moving the people to an assembly center [AC] site).

- For individuals arriving from the dangerous fallout zone, selfdecontamination will be possible through removal of surface contamination.

- After triage and initiation of minor treatments where applicable, available transportation assets will evacuate victims to medical care $(\mathrm{MC})$ or $\mathrm{AC}$ sites as appropriate, some of which may be at a substantial distance.

- Roads and logistics should not impose serious limitations on the capabilities.

- Function may be the same as AC sites in some cases.

\section{Sites}

MC sites will be primarily predetermined locations and may include hospitals; medical centers; nursing facilities; medical clinics; alternate care facilities such as federal medical stations; and nationwide medical facilities such as Radiation Injury Treatment Network sites, ${ }^{12}$ cancer centers, burn centers, or trauma centers, which can provide specialty care for patients with burns, bone marrow depletion, or other complications of trauma and 
radiation. Some of the facilities nearest to the blast will not be operational due to loss of infrastructure. The MC sites near the detonation location will likely be overwhelmed by people seeking care and would be another priority for pushing resources to relieve acute shortages and to provide transportation assets to move patients to definitive care outside the immediate blast area. These sites are most in need of preestablished triggers, triage protocols, and plans to allow for fair allocation of resources and implementation of crisis standards of care.

\section{AC Sites}

AC sites will be evacuee-receiving registry centers and temporary shelters where people may receive food, shelter, and other

\section{FIGURE 4}

\section{Resource availability vs demand after a nuclear detonation}
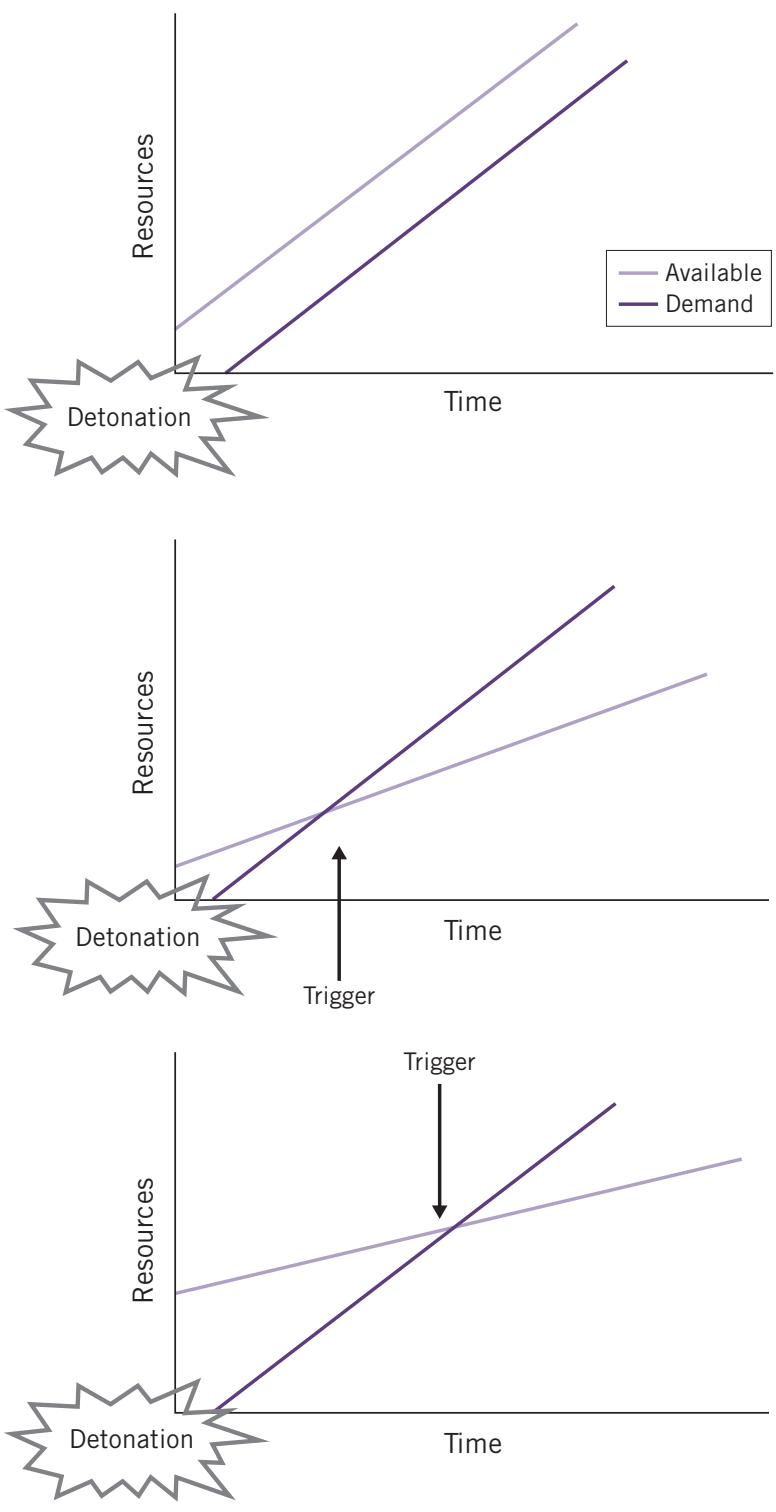

human services. These predesignated sites are for people with no or minimal requirements for medical care. People may arrive directly or may have been directed from other sites. Victim registration and population monitoring are key components involving local and federal authorities. Those who enter $\mathrm{AC}$ sites and are asymptomatic but require medical attention or may have had significant radiation exposure (based on location postdetonation), will be referred for follow-up and perhaps biodosimetry studies to determine dose (eg, blood counts).

\section{Evacuation/Logistics Centers}

Evacuation/logistics centers will be set up to transport out victims and evacuees and to transport in supplies and personnel. Despite the size of a nuclear detonation incident, those not near the epicenter or within the plume may safely remain where they are or may return as infrastructure is restored.

\section{Real-Time Mapping}

For the RTR medical response approach to fairly leverage scarce resources, response personnel must know the various treatment locations so that the movement of patients and resources can be effective and efficient. The MedMap project ${ }^{27}$ at the Office of the Assistant Secretary for Preparedness and Response has created an interactive geographic information system map that will include MC sites, AC centers, and other locations of interest for transportation hubs and points of distribution to create a common operating picture to implement the RTR concept. MedMap has the ability to overlay onto a broad range of physical maps (eg, roads, schools, weather) the key geographically modeled or actually sampled radiation level data, updated over time, from IMAAC ${ }^{18}$ and responders. MedMap will be made available to federal/state/local/tribal/territorial officials to allow all of the responders to share up-to-date situational awareness.

\section{Fatality Management}

Fatality management, per sé, is beyond the scope of the Scarce Resources for a Nuclear Detonation Project and is covered in the Planning Guidance for Response to a Nuclear Detonation ${ }^{2}$ and the Centers for Disease Control and Prevention's Guidelines for Handling Decedents Contaminated with Radioactive Materials. ${ }^{8}$

\section{SCARCE RESOURCES PRINCIPLES}

As described in the preceding sections, a substantial nuclear detonation will cause physical effects and a great number of casualties that will require an organized medical response to save lives. With this type of incident, the demand for resources to treat casualties will far exceed what is available. The goal of planning is to have sufficient resources (space, staff, and supplies $)^{28}$ to meet the needs; and when an imbalance of needs and resources exists, the goal is to restore resources to meet the demand as promptly and efficiently as possible. This principle, illustrated in Figure $4,{ }^{29}$ has profound implications for the triage and treatment of casualties and of people already receiving care within the medical facilities affected by the detonation. 
In a nuclear detonation, the relationship between resources and demand will vary with the location and time after the detonation. The shape and steepness of the availability and demand curves in Figure 4 are presented for conceptual illustration only. The top panel shows that resource demand increases over time. In an ideal world, the available supply of resources keeps pace with the demand, and no need exists to adjust standards of medical care. In the center panel, with an incident that has a steeper increase in demand than in available resources, a point occurs at which demand exceeds resources, which is the trigger for consideration and eventual implementation of contingency or crisis care ${ }^{1}$ this will vary depending on the relationship between the demand and the available resources (as the demand further exceeds available resources). For medical care facilities and resources close to a nuclear detonation, the trigger will occur soon after the detonation. The bottom panel shows that the goal of preparedness planning is either to avoid or (at least) to delay the trigger for crisis standards by enhancing the availability of assets to meet the demands. The goal of response operations is to be able to target allocation of resources in a fair manner so that the supply keeps pace with the demand.
A growing body of literature addresses the issue of allocation of scarce resources and the impact of resource shortages on the medical standard of care. Planning guidance published by the Agency for Health Care Research and Quality in collaboration with the Office of the Assistant Secretary for Preparedness and Response in $2007^{4}$ offers approaches and strategies to enhance and optimize resource availability in catastrophic incidents such as pandemic influenza or improvised nuclear device detonation. Prehospital care, hospital care, alternate-care sites, and palliative care are considered in the guidance.

An essential tenet of scarce resource allocation is that strategies can be used to optimize the available resources to maintain, as much as possible, conventional patient care delivery. Six basic strategies have been suggested for managing care in scarce resource situations ${ }^{28,30}$ :

- Preparedness - Stock disaster supplies and increase par levels on commonly needed items such as tetanus vaccines, laceration trays, narcotic analgesics, and dressing (reference published supply lists for disaster stocking).

\section{FIGURE 5}

\section{Continuum of incident care and implications for standards of care}

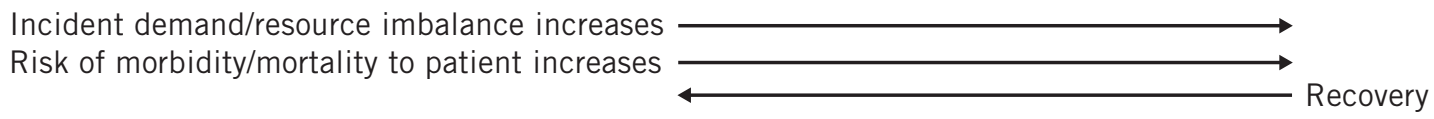

\begin{tabular}{|c|c|c|c|c|c|}
\hline & Conventional & \multicolumn{2}{|c|}{ Contingency } & \multicolumn{2}{|l|}{ Crisis } \\
\hline Space & $\begin{array}{l}\text { Usual patient } \\
\text { care space fully } \\
\text { utilized }\end{array}$ & \multicolumn{2}{|c|}{$\begin{array}{l}\text { Patient care areas repurposed (PACU, } \\
\text { monitored units for ICU-level care) }\end{array}$} & \multicolumn{2}{|c|}{$\begin{array}{l}\text { Facility damaged/unsafe or } \\
\text { nonpatient care areas } \\
\text { (classrooms, etc) used for } \\
\text { patient care }\end{array}$} \\
\hline Staff & $\begin{array}{l}\text { Usual staff } \\
\text { called in and } \\
\text { utilized }\end{array}$ & \multicolumn{2}{|c|}{$\begin{array}{l}\text { Staff extension (brief deferrals of nonemergent } \\
\text { service, supervision of broader group of patients, } \\
\text { change in responsibilities, documentation, etc) }\end{array}$} & \multicolumn{2}{|c|}{$\begin{array}{l}\text { Trained staff unavailable or } \\
\text { unable to adequately care for } \\
\text { volume of patients even with } \\
\text { extension techniques }\end{array}$} \\
\hline Supplies & $\begin{array}{l}\text { Cached and } \\
\text { usual supplies } \\
\text { used }\end{array}$ & \multicolumn{2}{|c|}{$\begin{array}{l}\text { Conservation, adaptation, and substitution of } \\
\text { supplies with occasional reuse of select supplies }\end{array}$} & \multicolumn{2}{|c|}{$\begin{array}{l}\text { Critical supplies lacking possible } \\
\text { reallocation of life-sustaining } \\
\text { resources }\end{array}$} \\
\hline $\begin{array}{l}\text { Standard } \\
\text { of care }\end{array}$ & Usual care & \multicolumn{2}{|c|}{ Functionally equivalent care } & \multicolumn{2}{|c|}{ Crisis standards of care } \\
\hline \multirow{2}{*}{\multicolumn{2}{|c|}{$\begin{array}{l}\text { Usual operating } \\
\text { conditions }\end{array}$}} & & & & \multirow{2}{*}{$\begin{array}{l}\text { Austere operating } \\
\text { conditions }\end{array}$} \\
\hline & & $\begin{array}{l}\text { Indicator: potential } \\
\text { for crisis standards }{ }^{2}\end{array}$ & \multicolumn{2}{|c|}{$\begin{array}{l}\text { Trigger: crisis standards } \\
\text { of care }{ }^{3}\end{array}$} & \\
\hline
\end{tabular}

1) Unless temporary, requires state empowerment, clinical guidance, and protection for triage decisions and authorization for alternate care sites/techniques. Once situational awareness achieved, triage decisions should be as systematic and integrated into institutional process, review, and documentation as possible.

2) Institutions consider impact on the community of resource utilization (consider "greatest good" vs. individual patient needs-for example, conserve resources when possible) but patient-centered decision-making is still the focus.

3) Institutions (and providers) must make triage decisions balancing the availability of resources to others and the individual patient's needs-shift to community-centered decision-making. 
- Substitute - Use a clinically equivalent item or staff person.

- Adapt - Use items or technologies to provide sufficient care (use transport ventilators or anesthesia machines instead of full-featured ventilators), use staff with similar or congruent skill sets (specialty surgeons assisting with trauma surgeries), or adapt locations of care (performing surgical procedures outside of the operating room environment).

- Conserve - Use less of a resource by lowering dosages or changing utilization practices.

- Reuse - After appropriate disinfection/sterilization, reuse supplies.

- Reallocate - Remove a therapy/monitor from 1 patient to give to another with a higher chance of benefit or a greater need (reallocation of ventilator).

For situations in which the resource-allocation strategies are not effective in maintaining conventional patient care delivery, guidance is available for changing from conventional to contingency to crisis care ${ }^{1}$ as the supply and demand curves cross and diverge. Figure 5 shows that as the care evolves along this continuum of available resources, the standards of care will move from usual care to functionally equivalent care to crisis standards of care based on the amount of resources available relative to demand. In the contingency setting, adaptations are put into effect (see above) to provide functionally equivalent levels of care. As available resources of "space, staff, and supplies" decline relative to demand, the institution will enter a state of crisis standards of care.

In a crisis situation a substantial change is made in usual health care operations and the level of care delivered, which is made necessary by a pervasive or catastrophic disaster. The change in the level of care is justified by specific circumstances and is formally declared by a state government in recognition that crisis operations will be in effect for a sustained period. The formal declaration of crisis standards of care enables specific legal/ regulatory powers and protections for health care workers in the necessary tasks of allocating and using scarce medical resources and implementing alternate care facility operations. ${ }^{1}$

Ideally, preparation will have been done and criteria established for this transition, discussed further in the article by Caro and colleagues. ${ }^{31}$ Medical facilities that are located close to a nuclear detonation will become the focal point for response, so plans for their rapid transition to crisis standards of care are crucial. The frontline clinicians will make reactive triage and treatment decisions before the more proactive triage infrastructure is put in place. ${ }^{1}$ An important consideration is that resources may be available but not distributed effectively to meet needs. By planning for a nuclear detonation response using the RTR system, ${ }^{26}$ the ethical principles as outlined by Caro et al, ${ }^{31}$ and the triage scheme proposed by Coleman et al, ${ }^{15}$ it may be possible to enhance the utility of the available resources to meet the significant casualties that can be expected with this scenario. Although this will not prevent the need for crisis stan- dards of care for an incident of this magnitude, it may delay the crossing of the resource and demand lines (Figure 4, bottom) and help them return as quickly as possible to a situation in which resources satisfy demand.

\section{Strategies for Scarce Resources Situations}

Planning for a potential influenza pandemic stimulated much of the recent work on allocation of scarce resources. In certain types of scenarios, one can expect shortages of particular types of equipment and supplies. For example, much discussion and debate has occurred about how one would allocate ventilators and associated supplies (eg, circuits) during an influenza pandemic. ${ }^{32,33}$

A series of articles from the American College of Chest Physicians offers practical guidance for the provision of mass critical care with progressively scarcer resources. ${ }^{4,28,30,34,35}$ These articles also describe the necessity of a regionalized system that attempts to manage scarcity to provide as consistent a level of care as far as is possible across the affected area. The goal is to allocate resources with fairness as an overarching principle to provide the greatest good for the greatest number of people, that is, to save lives and provide comfort care to the extent possible.

\section{CONCLUSIONS}

The present article sets the context for this special issue on allocation of scarce resources following a nuclear detonation. It describes the structural damage, casualty estimates, and proposed medical response to this type of catastrophic incident. After a nuclear detonation, operations will occur in a scarce resources environment. The allocation of scarce resources should be based on the overarching ethical principle of fairness in triage and provision of care in such a way as to maximize the effectiveness of interventions. ${ }^{31}$ Planning and responses will need to be flexible, adjusting to changing conditions on the ground. Initially, usual standards of care will be replaced with crisis standards of care, particularly for facilities in proximity to the detonation. ${ }^{1}$ This special issue provides a foundation for the substantial preparation needed before a nuclear detonation to fairly allocate resources to provide the greatest good for the greatest number in response to this catastrophic incident.

Author Affiliations: Drs Knebel, Coleman, Cliffer, Bader, Parker, and Yeskey, Ms Murrain-Hill, and Mr Hrdina are with the Office of the Assistant Secretary for Preparedness and Response, Department of Health and Human Services; Mr McNally and Drs Oancea and Jacobs are with Science Applications International Corporation; $\mathrm{Mr}$ Buddemeier is with the Lawrence Livermore National Laboratory, Department of Energy; Dr Hick is with the Hennepin County Medical Center, University of Minnesota; Dr Weinstock is with the Dana-Farber Cancer Institute, Harvard Medical School; Dr Taylor is with the Executive Office of the President, Office of Science and Technology Policy; Dr Matzo is with the College of Nursing, University of Oklahoma; and Ms Livinski is with the National Institutes of Health Library.

Drs Knebel, Coleman, and Cliffer contributed equally to this article.

Correspondence: Address correspondence and reprint requests to Dr Ann R. Knebel, 200 Independence Ave SW, Suite 638G, Washington, DC 20201 (e-mail: ann.knebel@hhs.gov). 
Received for publication September 19, 2010; accepted January 20, 2011.

The US Department of Health and Human Services (DHHS) provided funding to support this publication and convene the authors. The contents of the articles represent the personal views of the individual authors and do not necessarily express the opinion or policy of DHHS or its components. No statement in the articles should be construed as an official position of DHHS or its components.

Author Disclosures: The authors report no conflicts of interest.

Acknowledgments: The authors thank Susan Coller-Monarez of the Office of Science and Technology, Department of Homeland Security for initial organization of the Scarce Resources for a Nuclear Detonation Project.

\section{REFERENCES}

1. Institute of Medicine. Guidance for Establishing Crisis Standards of Care for Use in Disaster Situations: A Letter Report. http://www.iom.edu/Reports/2009 /DisasterCareStandards.aspx. Accessed April 2, 2010.

2. Planning Guidance for Response to a Nuclear Detonation. 2nd ed. Washington, DC: Homeland Security Council, Interagency Policy Coordination Subcommittee for Preparedness and Response to Radiological and Nuclear Threats; May 6, 2010. http://hps.org/hsc/documents/Planning_Guidance _for_Response_to_a_Nuclear_Detonation-2nd_Edition_FINAL.pdf. Accessed February 7, 2011.

3. Institute of Medicine, Committee on Medical Preparedness for a Terrorist Nuclear Event. Assessing Medical Preparedness to Respond to a Terrorist Nuclear Event: Workshop Report. Washington, DC: National Academies of Science; 2009.

4. Agency for Healthcare Research and Quality. Mass Medical Care With Scarce Resources; A Community Guide. AHRQ Publication No. 07-0001. http: //www.ahrq.gov/research/mce/mceguide.pdf. Published February 2007. Accessed April 2, 2010.

5. National Library of Medicine, National Institutes of Health. Radiation Emergency Medical Management (REMM) Web site. http://www.remm.nlm .gov. Accessed April 2, 2010.

6. US Department of Homeland Security. National Planning Scenarios. Scenario 1: nuclear detonation-10-kiloton improvised nuclear device (IND), version 20.1. http://media.washingtonpost.com/wp-srv/nation /nationalsecurity/earlywarning/NationalPlanningScenariosApril2005 .pdf. Accessed April 2, 2010.

7. Federal Emergency Management Agency, US Department of Homeland Security. National response framework: radiological/nuclear incident annex. http: //www.fema.gov/pdf/emergency/nrf/nrf_nuclearradiologicalincidentannex .pdf. Published June 2008. Accessed November 20, 2010.

8. Wood CM, DePaolo F, Whitaker RD. Guidelines for Handling Decedents Contaminated With Radioactive Materials. http://www.bt.cdc.gov/radiation /pdf/radiation-decedent-guidelines.pdf. Published 2007. Accessed April 2, 2010.

9. Matzo M, Wilkinson A, Lynn J, Gatto M, Phillips S. Palliative care considerations in mass casualty events with scarce resources. Biosecur Bioterror. 2009; 7(2):199-210

10. Buddemeier BR, Dillion M. Key Response Planning Factors for the Aftermath of a Nuclear Detonation. LLNL-TR-410067. http://www.remm.nlm .gov/IND_ResponsePlanning_LLNL-TR-410067.pdf. Published August 2009. Accessed April 2, 2010.

11. Bogucki S, Jubanyik K. Triage, rationing, and palliative care in disaster planning. Biosecur Bioterror. 2009;7(2):221-224, discussion 224.

12. Weinstock DM, Case C Jr, Bader JL, et al. Radiologic and nuclear events: contingency planning for hematologists/oncologists. Blood. 2008;111 (12):5440-5445.

13. Davids MS, Case C Jr, Confer DL, Weisdorf DJ, Weinstock DM. Medical management of radiation victims in the United States. Health Phys. 2010; 98(6):833-837.

14. Coleman CN, Knebel AR, Hick JL, et al. Scarce resources for nuclear detonation: project overview and challenges. Disaster Med Public Health Prep. 2011;5(Suppl 1):S13-S19.
15. Coleman CN, Weinstock DM, Casagrande R, et al. Triage and treatment tools for use in a scarce resources-crisis standards of care setting after a nuclear detonation. Disaster Med Public Health Prep. 2011;5(Suppl 1):S111-S121.

16. Ledney GD, Elliott TB. Combined injury: factors with potential to impact radiation dose assessments. Health Phys. 2010;98(2):145-152.

17. Vandre RH, Klebers J, Tesche FM, Blanchard JP. Electromagnetic pulse (EMP), Part I: Effects on field medical equipment. Mil Med. 1993;158 (4):233-236

18. Interagency Modeling and Atmospheric Assessment Center Web site. https: //imaacweb.llnl.gov/web/signIn.html. Accessed April 2, 2010.

19. DiCarlo AL, Maher C, Hick JL. Radiation injury after a nuclear detonation: medical consequences and the need for scarce resources allocation. Disaster Med Public Health Prep. 2011;5(Suppl 1):S32-S44.

20. Grace MB, Moyer BR, Prasher J, et al. Rapid radiation dose assessment for radiological public health emergencies: roles of NIAID and BARDA. Health Phys. 2010;98(2):172-178.

21. Prasanna PG, Blakely WF, Bertho JM, et al. Synopsis of partial-body radiation diagnostic biomarkers and medical management of radiation injury workshop. Radiat Res. 2010;173(2):245-253.

22. Levanon I, Pernick $A$. The inhalation hazard of radioactive fallout. Health Phys. 1988;54(6):645-657.

23. Peterson KR, Shapiro CS. Internal dose following a major nuclear war. Health Phys. 1992;62(1):29-40.

24. Casagrande R, Wills N, Kramer E, et al. Using the model of resource and time-based triage (MORTT) to guide scarce resource allocation in the aftermath of a nuclear detonation. Disaster Med Public Health Prep. 2011; 5(Suppl 1):S98-S110.

25. Emergency Medical Assistance Compacts Web site. Accessed April 2, 2010. http://www.emacweb.org.

26. Hrdina CM, Coleman CN, Bogucki S, et al. The "RTR" medical response system for nuclear and radiological mass-casualty incidents: a functional TRiage-TReatment-TRansport medical response model. Prehosp Disaster Med. 2009;24(3):167-178.

27. Office of the Assistant Secretary for Preparedness and Response. MedMap Web site. https://medmap.hhs.gov. Accessed November 20, 2010.

28. Hick JL, Koenig KL, Barbisch D, Bey TA. Surge capacity concepts for health care facilities: the CO-S-TR model for initial incident assessment. Disaster Med Public Health Prep. 2008;2(Suppl 1):S51-S57.

29. Knebel A. Presentation to the Institute of Medicine Forum on Medical and Public Health Preparedness for Catastrophic Events; May 21, 2008; Washington, DC.

30. Hick JL, Barbera JA, Kelen GD. Refining surge capacity: conventional, contingency, and crisis capacity. Disaster Med Public Health Prep. 2009; 3(2)(Suppl):S59-S67.

31. Caro JJ, DeRenzo EG, Coleman CN, et al. Resource allocation after a nuclear detonation incident: unaltered standards of ethical decision making. Disaster Med Public Health Prep. 2011;5(Suppl 1):S46-S53.

32. Powell T, Christ KC, Birkhead GS. Allocation of ventilators in a public health disaster. Disaster Med Public Health Prep. 2008;2(1):20-26.

33. Veterans Health Administration Pandemic Ethics Initiative Work Group. Meeting the Challenge of Pandemic Influenza: Ethical Guidelines for Leaders and Health Care Professionals in the Veterans Health Administration. http: //www.ethics.va.gov/activities/pandemic_influenza_preparedness.asp. Published July 2010. Accessed November 20, 2010.

34. Devereaux A, Christian MD, Dichter JR, Geiling JA, Rubinson L; Task Force for Mass Critical Care. Summary of suggestions from the task force for mass critical care summit, January 26-27, 2007. Chest. 2008;133(5) (Suppl):1S-7S.

35. Devereaux AV, Dichter JR, Christian MD, et al; Task Force for Mass Critical Care. Definitive care for the critically ill during a disaster: a framework for allocation of scarce resources in mass critical care: from a Task Force for Mass Critical Care summit meeting, January 26-27, 2007, Chicago, IL. Chest. 2008;133(5)(Suppl):51S-66S. 